\title{
ТЕОРИЯ И ПРАКТИКА АЛЬТЕРНАТИВНОГО УРЕГУЛИРОВАНИЯ СПОРОВ
}

\author{
(c) 2019 Тимошенко Татьяна Викторовна \\ кандидат философских наук, доцент \\ Южный федеральный университет, Россия, Таганрог \\ E-mail: tvtimoshenko@sfedu.ru
}

В статье рассмотрена проблема обеспечения безопасности человека и гражданина со стороны государства через гарантию его прав и свобод в современном гражданском обществе, которое обладает внутренним потенциалом для реализации конституционного права на судебную защиту, в том числе и посредством проведения альтернативных процедур разрешения правовых конфликтов. Дается представление правового конфликта как особой разновидность социального конфликта. Предлагаются альтернативные, более гибкие и диспозитивные, способы урегулирования конфликтов, которые позволяют выработать наиболее правильное решение проблемы. Использование медиации гарантирует выгоду для обеих сторон: способствует укреплению партнерских отношений, формированию правовой культуры мирного и самостоятельного разрешения конфликтных ситуаций участниками гражданского оборота. Рассмотрены проявления инерции и даже сопротивления институту медиации в сознании граждан. Делается вывод, что для того, чтобы медиация стала востребованной в процессе разрешения правовых конфликтов, необходима ее популяризация и обучении ее азам. Эта процедура может быть встроена в функционирующее гражданское общество.

Ключевые слова: правовой конфликт, медиация, права и свободы человека и гражданина.

Распространение альтернативного разрешения споров в современном обществе связано с процессами глобализации и демократизации, позволяющими распространять позитивный опыт разрешения правовых конфликтов, унифицировать процедуры переговоров, что способствует росту экономических, правовых, культурных и других взаимосвязей как между отдельными физическими и юридическими лицами, так и между государствами в целом. Процессы интеграции России в международное сообщество находят свое отражение во всех сферах общественного устройства, включая семью, экономику, труд и государственное управление. Динамика общественных отношений в современном мире требуют новых нестандартных подходов к разрешению возникающих правовых споров и конфликтов. Поэтому актуальным становится вопрос о готовности российского общества оценить преимущества способов альтернативного разрешения споров в области защиты прав человека.

В последнее время особое значение приобретают механизмы саморегулирования, когда субъекты правоотношений получают возможность самостоятельно устанавливать правила поведения и контролировать их соблюдение в процессе разрешения споров. Повышение от- ветственности участников гражданского оборота позволило государству на основе законодательства делегировать часть своих полномочий в определенных сферах институтам гражданского общества, включая, например, институт медиации. Анализ судебных реформ, проведенных во второй половине XX века в странах континентальной Европы, показывает процесс отказа от «государственного патернализма» при разрешении правовых споров, когда оно осуществляется исключительно в ходе правоприменительной практики путем вынесения обязательного для исполнения решения. Переход к демократии и плюрализму, то есть к признанию необходимости обеспечения конфликтующим лицам права выбора способа урегулирования их разногласий, позволяет использовать альтернативные процедуры в российском правовом пространстве.

Современное российское государство и общество находятся в процессе трансформации и переосмысления сущности процессов разрешения юридических конфликтов, что вполне достижимо в условиях роста правового сознания и правовой культуры людей. Поэтому актуальной, как представляется, становится проблема построения новой смысловой модели взаимоотношения людей при разрешении правовых конфликтов, в рамках которой достигается не- 
кий консенсус, позволяющий, с одной стороны, строить долговременные отношения, а с другой стороны - свидетельствует о том, что развитие альтернативного разрешения споров в стране является показателем роста гражданской сознательности, терпимости и цивилизованности ее граждан при разрешении возникающих юридических конфликтов.

Выделяют два основных направлений отношении развития альтернативных способов разрешения правовых споров в российском законодательстве: совершенствование институтов, которые гарантируют реализацию прав человека, и формирование и эволюция новых правовых форм внесудебного урегулирования споров [1, 329].

При этом любой внесудебный способ защиты не исключает одновременного или последующего обращения с иском в судебные органы, что является одним из проявлений конституционного права на судебную защиту. Этот факт как раз и позволяет судить о том, что альтернативные способы разрешения правовых споров, обладая некоторой автономностью, служат в качестве субсидиарных, дополнительных по отношению к государственным способам правовой защиты.

Следует отметить, что, несмотря на преимущества альтернативных способов разрешения правовых споров, существует ряд проблем, связанных с их использованием в области защиты прав человека. В частности, весьма дискуссионным является вопрос о возможностях отдельных альтернативных способов разрешения правовых споров в сфере защиты субъективных прав и свобод.

Существует множество теоретических исследований, посвященных проблеме использования посреднических процедур (в частности, медиации) для урегулирования споров о правах человека. Так, например, Уильям Г. О’Нил отмечает, что одной из задач, стоящих перед посредником, является выбор соответствующих методов освещения вопросов, касающихся прав человека, и их органичного включения в процесс проведения согласительной процедуры [2]. Это связано с тем, что основная цель медиации заключается в ликвидации конфликта и в предотвращении, тем самым, дальнейших нарушений прав человека. Данная процедура имеет, по мнению указанного автора, все шансы стать основой гармоничного развития отдельных ин- дивидов и устойчивого гражданского общества в целом.

Другой автор, Каролайн Риз в своей статье «Медиация в бизнес-ориентированных спорах по правам человека: возражения, возможности и препятствия» рассмотрела широко распространенное мнение, что «медиация и споры о правах человека, в лучшем случае, являются «плохими соседями», а возможно даже и полностью несовместимы по своей сути» [3, 4]. Проведя сравнительный анализ судебного разбирательства и медиации как двух возможных вариантов достижения справедливости и правосудия, автор приходит к выводу, что она (то есть медиация) имеет ряд неоспоримых преимуществ при защите прав человека. Данная процедура усиливает роль человеческого фактора в процессе отстаивания собственных прав (например, путем устранения возможного дисбаланса сил между сторонами в споре и так далее), и, таким образом, вносит дополнительный вклад в развитие концепции гуманизации прав человека.

Д. Христопулос и Н. Диамандурос в статье «Традиционные механизмы защиты прав человека и рост роли медиации в Юго-Восточной Европе» высказывают идею, что эволюция механизма защиты прав человека состояла из четырех этапов [4, 1]. Юридическое оформление этого механизма началось во Франции с принятия Декларации прав человека 1789 года, провозгласившей личные, политические, экономические права человека и право на судебную защиту. Развитие основных конституционных гарантий прав человека и гражданина продолжилось вплоть до создания неправительственных средств их правовой защиты. Установление института медиации можно рассматривать в качестве стадии процесса эволюции механизма защиты прав человека по той причине, что он представляет собой важный этап в широком эволюционном процессе, связанном гуманизацией, демократизацией общественных отношений и реальным обеспечением верховенства закона.

Еще одна из проблем альтернативного разрешения споров в области защиты прав и свобод человека связана с зависимостью эффективности данных процедур одновременно от многих факторов (в частности, от предмета спора, от взаимоотношений и целей спорящих сторон, от квалификации посредника и пр.). К примеру, эффективным способом защиты экономических прав личности может являться проведение пе- 
реговоров при заключении договора. Тем не менее, результативность данного согласительного способа далеко не всегда одинакова. Она может быть высока в ситуации, когда стороны заинтересованы в подписании договора. Однако эффективность переговоров существенно снизится при обсуждении неисполнения или ненадлежащего исполнения одним из контрагентов условий уже заключенного договора [5, 93]. В данной ситуации на эффективность переговоров может негативно повлиять и временной фактор, то есть длительность того периода, когда соглашение не исполнялось или исполнялось ненадлежащим образом. Иными словами, из средства достижения взаимовыгодного решения и способа урегулирования спора переговоры способны трансформироваться в орудие затягивания времени. В то же время эффективность обращения к судебной защите, как правило, обусловлена наличием правомерного основания для подачи искового заявления и его приемлемых доказательств.

Следующим спорным вопросом в практике применения альтернативных способов разрешения правовых споров является проблематика личности посредника или другими словами кто же вообще может выступать третьим лицом в споре о правах человека?

К примеру для третейского разбирательства, особенностью которого является наибольшая приближенность к разбирательству в государственном суде [6, 68], предполагающая принятие решение исключительно из оценки ситуации на основе действующего законодательства, данный вопрос не является проблемным. Требования, предъявляемые к третейскому судье, носят формальный характер и прямо прописаны в статье 8 ФЗ от 24 июля 2002 года № $102-Ф 3$ «О третейском суде в РФ» [7]. Однако применимо к переговорам и медиации, где принимаемое решение опирается далеко не только на правовые нормы, личность посредника является одним из факторов, определяющих результат альтернативной процедуры.

Спецификой переговоров в России является практически полное отсутствие их нормативного регулирования (исключение составляют лишь нормы трудового законодательства о коллективных переговорах [8]). Из всех альтернативных способов урегулирования правовых споров переговоры являются, пожалуй, одним из самых распространенных, поскольку для них требуется только наличие согласия сторон. Соответствен- но, посредником (при необходимости его участия для защиты прав и свобод человека) может выступать любое лицо, кандидатура которого удовлетворяет интересам спорящих.

Проведенный автором анализ ряда научных публикаций как отечественных, так и зарубежных авторов на предмет того - кто же вообще может быть посредником и какими чертами характера и профессиональными навыками такой человек должен обладать $[9,31]$, позволяет сделать вывод о том, что вопрос личности медиатора является одним из наиболее дискуссионных как среди теоретиков, так и практиков:

- во-первых, по причине установленного в законе возраста, ведь молодые люди, не имеющие достаточного жизненного и профессионального опыта, далеко не всегда смогут внушить доверие спорящим;

- во-вторых, существуют различия во мнениях, относительно уровня образования медиатора и его профессиональной подготовки.

Так, некоторые ученые-правоведы и практикующие юристы полагают, что медиация - это сугубо психологическое разрешение конфликтов, заниматься которым могут лишь профессиональные психологи. Зачастую у юристов медиация ассоциируется с психоанализом как способом применения внушения. Тем не менее, на наш взгляд, посредничество не является привилегией психологов. Конечно же медиация, будучи способом разрешения споров с помощью переговоров, предполагает определенное психологическое воздействие с целью достижения примирения сторон. Но на самом деле не это в ней главное и медиацией могут заниматься люди самых разных специальностей в силу ее междисциплинарного характера, причем в странах, где она популярна, процент юристов среди медиаторов достаточно высок.

В противоположность указанному мнению другие ученые считают, что законодателю следовало бы более четко ограничить круг лиц, имеющих право на осуществление этой деятельности, а именно - нормативно закрепить требование о наличии у медиатора высшего юридического образования. «Отсутствие в законопроекте элементарных требований, предъявляемых к профессиональной подготовке будущего медиатора, его моральным и деловым качествам, открывает двери в мир медиации всем желающим»,- пишет С. С. Колобашкина [5, 95].

Ю.Е. Пальцев полагает, что законодатель- 
ное закрепление деятельности медиатора как на профессиональной, так и на непрофессиональной основе, приводит к тому, что закон регулирует осуществление медиации не только в правовой, но и в иных сферах общественной жизни. «Такое положение,- утверждает он,- представляется недопустимым ввиду невозможности адекватного правового регулирования некой универсальной медиативной деятельности посредством единого нормативного акта. Законодателю следовало бы распространить сферу действия Закона исключительно на область разрешения правовых конфликтов, указав, в частности, в качестве обязательного требования к медиатору наличие высшего юридического образования» $[9,73]$. Такого же мнения придерживается и М. Морозова, которая отмечает, что медиатору необходимо быть «профессиональным знатоком правовых последствий любого конфликта, иначе - дипломированным юристом» $[10,9]$.

В качестве краткого резюме целого ряда имеющихся точек зрения, мы можем сказать, что все авторы соглашаются, что посредник должен быть нейтральным, независимым, иметь профессиональный и жизненный опыт и отличную репутацию. По нашему мнению, в связи со сложностью самой процедуры медиации, а также характера и причин конфликтов, не каждый может это понять и рекомендовать правильные способы разрешения правовых споров. Поэтому возраст и уровень образования приобретают большое значение и должны быть изменены в сторону их увеличения. Так, например, в программу подготовки медиаторов стоит включить изучение базовых юридических дисциплин. Также, проведенный анализ биографий медиаторов, руководивших успешно завершенными процедурами (например, медиации при реализации проекта расширения Франкфуртского аэропорта [12] и других) показал, что все посредники были представителями разных профессий и разных слоев общества (в названном случае - политик, предприниматель и священник). Каждый из них имел свое собственное прошлое, профессиональные навыки и личные качества, стабильное финансовое положение и общественное признание. Мы считаем, что все названные качества помогают обеспечить нейтралитет и независимость посредников, тем самым способствуя надлежащей защите прав и свобод участников процедуры.
Другим спорным вопросом в практике применения альтернативных способов разрешения правовых споров о правах и свободах человека является проблема формы и исполнимости принимаемого решения. Отсутствие в законодательстве норм, предоставляющих заинтересованной стороне право требования документального оформления результатов проведенных переговоров, способно негативно повлиять на привлекательность и эффективность данного внесудебного порядка для сторон спора.

Одной из важнейших черт медиации является добровольная исполнимость медиативного соглашения, поскольку оно должно быть реалистичным, в силу того, что стороны сами принимают решение, взвешивая имеющиеся возможности и желания, что предполагает сознательность и добросовестность участников процедуры. Поэтому для ее эффективного использования в обществе должен быть достигнут достаточно высокий уровень правосознания населения, поскольку в этом случае необходимым является наличие психологической готовности к компромиссу при урегулировании конфликта. Кроме того, медиативное соглашение подлежит исполнению на основе принципов добровольности и добросовестности сторон, но в то же время ему можно придать и законную силу путем передачи в третейский или мировой суд для последующего утверждения в качестве мирового соглашения.

В юридической литературе существует мнение, что медиация хороша потому, что в условиях большого процента неисполняющихся судебных решений, стороны будут готовы идти на компромиссы только ради того, чтобы решить проблему быстрее. Но подобное утверждение содержит либо незнание современных реалий, либо умышленную подмену понятий. Проблема состоит в том, что достижение любого соглашения между сторонами не гарантирует мгновенного его исполнения, с одной стороны, а с другой - нет и механизма, обеспечивающего исполнение заключенного с помощью медиатора соглашения. Можно согласиться с мнением о том, что «между тем впоследствии соглашение так же успешно не выполняется, обиженная сторона обращается в суд и получает такое же судебное решение, которое могла получить раньше, но поддалась стремлению к компромиссу» $[13,17]$. Поэтому в условиях отсутствия механизма обеспечения исполнения медиативного со- 
глашения существует точка зрения, что длительные переговоры, которые должны привести к мирному соглашению, служат лишь уловкой для недобросовестных граждан, позволяющей затянуть решение вопроса на неопределенное время.

Рассмотренные выше проблемы альтернативного разрешения споров и защита прав и свобод человека в комплексе порождают непопулярность некоторых видов альтернативного разрешения споров в отечественном правовом пространстве. Еще несколько лет назад, рассуждая о состоянии института медиации в России, П.В. Крашенинников отметил, что «в настоящее время, при отсутствии правовых условий для развития медиации, предприниматели, попав в конфликтную ситуацию, более склонны обратиться за помощью к власти, чем к медиатору. Для граждан, не связанных с экономическими спорами, данная процедура вообще не известна и не рассматривается как альтернатива судебной. В связи с этим процент рассмотрения бытовых споров, вытекающих как из гражданских, так и семейных, трудовых отношений с участием медиатора, очень низкий» [14]. К сожалению, за прошедшие годы ситуация практически не изменилась. Отсутствие принуждения со стороны государства оставляет медиацию «на задворках» механизмов гарантирования и защиты прав человека [15, 23].

Решение данной проблемы лежит в области использования двух основных правовых моделей реализации процедуры медиации, а именно: частную и интегрированную. Частная медиация представляет собой самостоятельный вид профессиональной деятельности по разрешению юридических споров. Использование данной модели предполагает введение отдельных организационно-правовых форм осуществления деятельности по проведению примирительных процедур, которые обеспечивают институциализацию медиации как альтернативного способа урегулирования правовых споров. Зачастую это достигается посредством принятия отдельных нормативно-правовых актов, которые устанавливают основы медиации как внеюрисдикционной процедуры через сферу ее применения, правовые принципы и гарантии, требования, предъявляемые к медиаторам и организациям, оказывающим помощь в урегулировании споров посредством медиации и тому подобное.

Необходимо отметить, что частная модель медиации не может осуществляться в деятельности юрисдикционных органов. Для их участия в популяризации примирительных процедур принято использовать конструкцию интегрированной медиации, которая рассчитана на особенности юрисдикционной деятельности и учитывает специфику ее осуществления. Интегрированная медиация - это специальная процедура и форма деятельности юрисдикционных органов (судов, нотариата, судебных приставов-исполнителей и так далее), целью которой является достижение примирения сторон в рамках юридического процесса. Если обратиться к зарубежному опыту применения медиации, то можно сделать вывод, что использование интегрированной модели эффективно в рамках деятельности различных государственных органов, уполномоченных на разрешение правовых споров. Основной задачей государства является выбор оптимальной модели такой медиации и ее органичное внедрение в существующую юрисдикционную процедуру.

Исходя из опыта последних лет, медиация стала востребованной в процессе разрешения правовых конфликтов, но для того, чтобы она трансформировалась в эффективный институт российского правового пространства, необходимо использование комплексного подхода, сочетающего в себе развитие как частной, так и интегрированной моделей медиации в совокупности с различными медиационными техниками в профессиональной юридической деятельности. Благодаря принятию специального законодательства в России созданы условия для постепенного внедрения процедуры медиации в отечественную правовую культуру. Вступлением в силу федеральных законов «Об альтернативной процедуре урегулирования споров с участием посредника (процедуре медиации)» и «О внесении изменений в отдельные законодательные акты Российской Федерации в связи с принятием Федерального закона «Об альтернативной процедуре урегулирования споров с участием посредника (процедуре медиации)» [16] также было положено начало для развития частной модели медиации. Тем не менее, чтобы медиация стала реальной альтернативой судебному рассмотрению споров, помимо принятия соответствующего законодательства еще необходимо преодолеть несколько достаточно сложных задач, в частности:

- сформировать в стране корпус профессио- 
нальных медиаторов;

- разработать действенные механизмы согласования медиации с юрисдикционными процедурами и прочее.

Несмотря на различное отношение граждан к институту альтернативного разрешения правовых споров, он постепенно приобретает в России все большее и большее распространение вследствие ряда неоспоримых достоинств и преимуществ, которыми он обладает при разрешении правовых конфликтов. Альтернативное разрешение правовых споров получает широкое распространение там, где достаточно высок уровень правовой культуры спорящих, которые способны посмотреть на себя со стороны и исходить не только из своих собственных интересов, но и учитывать интересы контрагентов. Следовательно, данный институт - это не только порождение правовой культуры и юридической техники урегулирования конфликтов, но и способ формирования особой среды, в которой большое значение приобретают моральнонравственные качества граждан, способных самостоятельно разрешать возникающие споры. Дело заключается в том, что альтернативное разрешение правовых споров непосредственно связано с институтами гражданского общества и правового государства, в рамках которых обеспечивается свобода граждан, утверждение начал справедливости и безопасности общественных отношений.

Продвижение института альтернативного урегулирования правовых споров в любой стране имеет свои сложности, прежде всего, это необходимость преодоления инерцию об- щественного сознания. Так, например, один из таких способов - медиация, не является заимствованием из англо-американской правовой системы, поскольку такой способ примирения сторон был известен и более древним правовым культурам, включая отечественную историю государства и права. За последние десятилетия она значительно эволюционировала в связи с социально-экономическими и политическими изменениями в мире. Поэтому нет необходимости изобретать какие-либо новые досудебные способы урегулирования споров специально для нашей страны, когда такие методы давно используются и имеют позитивный результат в общемировой юридической практике.

В современном его понимании альтернативное разрешение правовых споров - это способы разрешения споров с привлечением профессиональных и непрофессиональных посредников, предоставляющих сторонам максимум возможностей и свободы для реализации собственных интересов. Общеизвестно, что способность договариваться позволяет избежать негативных последствий, если прекратить спор до обращения в суд. В случае с альтернативным разрешением правовых споров речь идет о достижении консенсуса, основанного на согласии сторон и на проявлении ими уважения к интересам и потребностям друг друга. При этом на сегодняшний день одной из первостепенных задач по интеграции института альтернативного разрешения правовых споров в российское правовое пространство является информирование о его сути и преимуществах, как отдельных граждан, так и профессиональных групп.

\section{Библиографический список}

1. Адвокат: навыки профессионального мастерства / Под ред. Л.А. Воскобитовой, И.Н. Лукьяновой, Л.П. Михайловой.-М.: Изд-во «Волтерс Клувер», 2006.-С. 329.

2. O’Neill W. G. Mediation and Human Rights / W. G. O’Neill. Geneva: Centre for Humanitarian Dialogue. - 2002. [Электронный ресурс] - Режим доступа: http://www.hdcentre.org/uploads/tx_news/168MediationandHumanRights. pdf - (Дата обращения: 20.12.2015).

3. Rees C. Mediation in Business-Related Human Rights Disputes: Objections, Opportunities and Challenges / C. Rees.- Harvard, 2010.- P. 4.

4. Christopoulos $D$. Traditional human rights protection mechanisms and the rising role of mediation in Southeastern Europe, Occasional paper / D. Christopoulos, N. Diamandouros. - Alberta, 2002. № 78.- P. 1.

5. Колобашкина С. С. Проблемы использования адвокатом переговоров и медиации как внесудебных средств разрешения спора / С. С. Колобашкина // Адвокат. - 2011.- № 2.- С. 93.

6. Кочетков А.В. Актуальные проблемы альтернативных способов разрешения споров // А.В. Кочетков. Международная и внутригосударственная правовая политика в условиях глобализации: проблемы теории и практики: сборник статей по материалам III ежегодной международной научной конференции. - 2011.C. 68 . 
7. Федеральный закон от 24 июля 2002 г. № 102-ФЗ (в ред. от 29 декабря 2015 г.) «О третейских судах в Российской Федерации» // Российская газета.-2002. 27 июля.- № 137.

8. Статьи 36-38 Трудового кодекса РФ.

9. Пальцев Ю.Е. Некоторые проблемы закона о медиации в России / Ю.Е. Пальцев // Российская юстиция. -2011. - № 1.- С. 73.

10. Морозова М. Третий, но не лишний / М. Морозова // Новые известия. - 2010. - 27 мая. - С. 9.

11. Spencer D. Mediation Law and Practice / D. Spencer, M. Brogan.- Cambridge, 2007.- P. 155-174. Monagan S. Problem Solving Mediation Training: Facilitator's Guide / S. Monagan, E. James. - 2010.- P. 73-77. Hopt K.J. Mediation: principles and regulation in comparative perspective / K. J. Hopt, F. Steffek. - Oxford, 2013.P. 56-57. Boulle L. Mediation: Skills and Techniques / L. Boulle, N. M. Alexander.- LexisNexis Butterworths, 2012. Whatling T. Mediation Skills and Strategies: A Practical Guide / T. Whatling. - Jessica Kingsley Publishers, 2012. Padula M. Mediation of Special Education Disputes and the Use of Participant Feedback: A Multi-state Study / M. Padula.-ProQuest, 2008.- P. 31.

12. Airport Region Mediation Competence Center [Электронный peсурс] - URL: http://airportmediation.org/jart/ prj3/armcc_airportmediation/main.jart?rel=en\&content-id=1308751074210\&reserve-mode=active. - Заглавие с экрана.-(Дата обращения: 12.01.2016).

13. Колковский Ю. Препятствия развитию медиации / Ю. Колковский // эж-ЮРИСТ.- 2007. 17 мая.-С. 17.

14. Ассоциация юристов России [Электронный ресурс].- Режим доступа: http:// www. alrf. ru/dynamic/press/ krasheninnikov-o-mediatsii.- Загл. с экрана. - (Дата обращения: 05.05.2013).

15. Рэндольф П. Поощрение к медиации / П. Рэндольф // Медиация и право._2010._№ 15._- С. 23.

16. Федеральный закон от 27 июля 2010 г. № 194-ФЗ «О внесении изменений в отдельные законодательные акты Российской Федерации в связи с принятием Федерального закона «Об альтернативной процедуре урегулирования споров с участием посредника (процедуре медиации)» // Российская газета.- 2010. 30 июля. - № 168 . 